\title{
PDF Marksheet Generator
}

\author{
Srushti Shimpi \\ PVPPCOE/Dept. of IT, Mumbai, 400022, India \\ Email: shimpisrushti@gmail.com
}

Sanket Mandare, Tyagraj Sonawane, Aman Trivedi, K. T. V. Reddy

PVPPCOE/Dept. of IT, Mumbai, 400022, India

sanketm64@gmail.com, tyagraj.sonawane@gmail.com, aman.trivedis@gmail.com, ktvreddy@gmail.com

\begin{abstract}
The Marksheet Generator is flexible for generating progress mark sheet of students. This system is mainly based in the database technology and the credit based grading system (CBGS). The system is targeted to small enterprises, schools, colleges and universities. It can produce sophisticated ready-touse mark sheet, which could be created and will be ready to print. The development of a marksheet and gadget sheet is focusing at describing tables with columns/rows and subcolumn sub-rows, rules of data selection and summarizing for report, particular table or column/row, and formatting the report in destination document. The adjustable data interface will be popular data sources (SQL Server) and report destinations (PDF file). Marksheet generation system can be used in universities to automate the distribution of digitally verifiable mark-sheets of students. The system accesses the students' exam information from the university database and generates the gadget-sheet Gadget sheet keeps the track of student information in properly listed manner. The project aims at developing a marksheet generation system which can be used in universities to automate the distribution of digitally verifiable student result mark sheets. The system accesses the students' results information from the institute student database and generates the mark sheets in Portable Document Format which is tamper proof which provides the authenticity of the document. Authenticity of the document can also be verified easily.
\end{abstract}

Index Terms - Grade Sheet and Mark-Sheet, Mark-Sheet Generation and PDF Marksheet

\section{INTRODUCTION}

The marksheet generator is a system which allows the digital automation of the mark-sheets of the students. The system will generate the mark-sheets in Portable Document Format which is globally accepted format for files. The PDF document is very difficult to modify and requires the use of the complex software.

To simply put, system is to provide the mark-sheet for credits based grading system in user friendly and secure manner. The credits based grading system enables a much require shift in focus from teacher-centric to learner-centric education. It also focuses on the continuous evaluation which will enhance the quality of education. It is very much essential to implement credits based grading system based higher education worldwide.

The efficiency of the system would increase in a leap and bounds considering the fact that system will be automated \& would be corruption free. Along with the above mentioned privileges, it also ensures security \& spreads the awareness about the university rules and regulation.

\section{REVIEW OF LITERATURE}

The marksheet generator is kind of a document generator. There have been number of technologies proposed to generate the document or reports.

\section{A. Existing System}

Digital Signature based mark-sheet generator: A digital signature or the digital signature scheme is type of asymmetric cryptography used to simulate the security properties of hand written signature on the paper. The output of signature process is digital signature. It provides authenticity and integrity to data ${ }^{[2]}$.

Digital academic transcript using encrypted $Q R$ code: Mark-sheet embed the digital form in mark sheet using encrypted QR code, so that any unauthorized user cannot retrieve any information ${ }^{[1]}$.

Predictive model for education: There are a set classification rules that were extracted from the decision tree to predict and classify the class label for each student [4]

Custom Report Generation: The modules are interrelated in a logical manner to report all clinical engineering services. Each user has a unique login name and a password, which are checked and verified by the system against the granted permissions of the respective user group. In addition, adequate mechanisms for easy and accurate data report and protection were installed in order to minimize incidents of incomplete or corrupted reports ${ }^{[3]}$.

Report Generator technical Specification: It provides the capability for users to create their own text, graph or diagram reports, or allow them to use the standard report supplied with Isograph software product ${ }^{[5]}$.

\section{B. Disadvantage of Existing System}

Association of digital signature and trusted time stamp: Digital signature algorithm and protocol do no inherently provide the certainty about the date and time at which underlying document was signed ${ }^{[2]}$.

Non repudiation: In cryptographic context, the word repudiation refers to any act disclaiming responsibility for message. It is used to remove old expired certificates from repository. It is matter for security policy and 
responsibility of authority to keep old certificates for a period of time if non-repudiation data service is provided [2].

Unavailability of hardware: Even though the use of QR code in a mark-sheet that possess ability to scan QR code. Also for scanning purpose one must have hardware which adds a cost to system.

Lack of user friendly interface: Due to use of DOS or user interfaces which are not user friendly. It also uses various difficult commands to complete the number of tasks. The existing system fails to provide a good user interface. Also understanding of the user interface of existing system is tedious and time consuming whereas the new system is self-explanatory and easy to use as far as user interface is concerned.

\section{PROPOSED SYSTEM}

The marksheet generator is to ensure an efficient certificate management using huge data and to provide mark-sheets for credit based grading system (CBGS) in very user friendly manner by not making it very complex.

The system being automated and generalized, the system ensures to reduce manual errors by reducing manual efforts. An added asset to the feature of system is that it aims at improving and easing out the work of the existing system in very sophisticated way.

The technology is rapid and able to generate, store \& display the mark-sheets of the students. The system provides advance reaction capabilities and automatic operator of the internal calculation based on university rules with the information from the database. It also works with various standards of the mark-sheets.

\section{WORKING}

In this proposed system, the admin of the system enters the marks of each student. That information will be stored in internal collection information database. In this system, percentage and grade is calculated manually.

The marksheet generation system is to ensure an efficient marksheet management using huge data and to provide mark-sheets for credit based grading system (CBGS) in very user friendly manner by not making it very complex.

As we describe in the existing system after the paper is check the marks goes to the mark sheet generator system. The admin of the system in this proposed system just enter the mark and information of the each student. That information will be stored in internal collection information database. In the system the percentage and grade is calculated manually.

After the marks of all the students is enter by the admin of the system by clicking the mark sheet generator button. Then application generates the mark sheet of all the students automatically with the grades calculated. Mark sheets will be in PDF format.PDF mark sheets cannot be easily tampered with and require use of complex software. The pdf file of mark sheet of every student will be stored in mark sheet database. And then application makes mark sheets available via internet on demand.

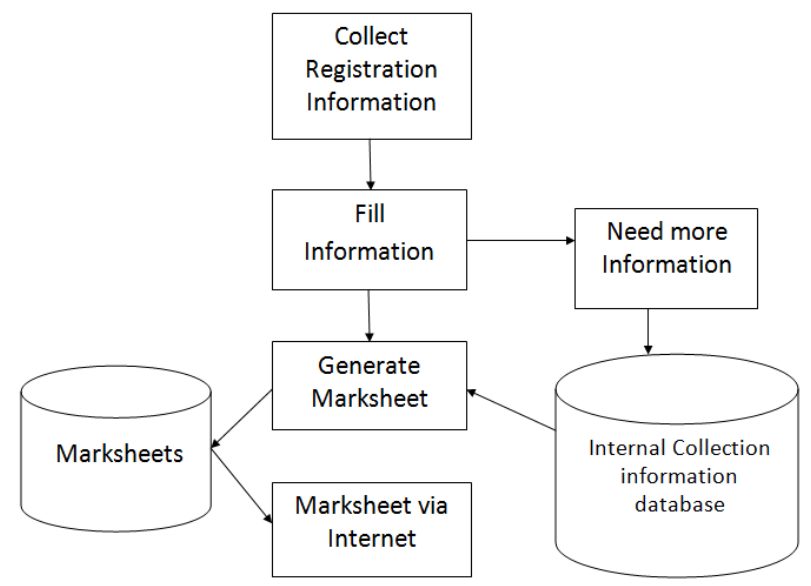

Fig. 1. System architecture of Marksheet generator

\section{AlgORITHM}

This is how our system will work. Steps for the implementation of system are as follow:

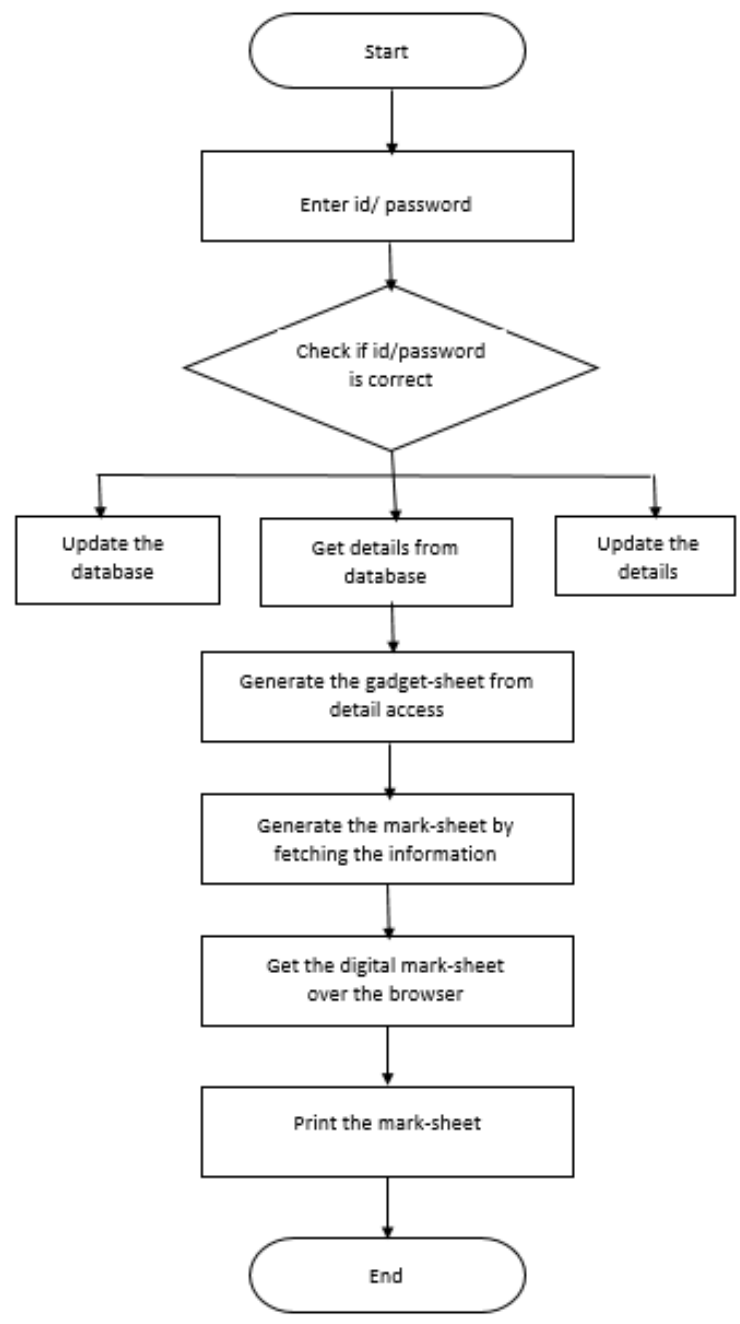

Fig. 2. Flowchart for Marksheet generator 
Step 1: If admin is operating the system, login id and password. If student is operating the system, they can access the system by providing the registration id.

Step 2: Check if provided login id and password or registration id is correct, if not go back to step 1 and if correct proceed for the step 3 .

Step 3: If admin is operating the system, he can access the system by updating the database, changing the data in the database and can get the required information from the database. If students are operating the system, the can only view the data.

Step 4: Then system will generate the gadget sheet of all the students and it calculates the grade and grade point of each and every student as per the Credit based grading system (CBGS).

Step 5: Then this system will generate the mark sheet by fetching the grades, pointers and credits from the gadget sheet previously developed.

Step 6: Then this information of students' marks are available to access to students by providing authentication. Admin will get requested mark sheet in PDF mark sheet for printing purpose. And only marks can be accessible to student.

Steps 7: These mark sheets then can be made printable by converting it into portable document format.

\section{TECHNOLOGY AND CONCEPT}

PHP is used for web development works as a server side scripting language and also it is used for general purpose programming. PHP code is interpreted by a web server with the PHP processor generates the resulting page which interprets the PHP code. It also includes interface capacity of command line and can be used standalone graphical application.

In this system input can be marks of the students of their theory exams, practical exams, internal assessment and term work. Grades and pointers of student can be calculated according to rules, formulae and ordinances.

The formulae for calculation of grade performance index (GPI):

Semester Grade Performance Index (SGPI): The performance of semester is indicated by a number called semester grade performance index. SGPI is weighted average of the grade points obtained in all the courses by the student during the semester.

$$
\text { SGPI }=\frac{C 1 G 1+C 2 G 2+\cdots+C n G n}{C 1+C 2+\cdots+C n}
$$

Cumulative Grade Performance Index (CGPA): An up to date of an overall performance of student from the time he/she enrolled in the university is obtained by calculating a number called cumulative grade performance index. It is calculated in similar manner of SGPI. CGPA is responsible to reflect final pass or fail status of student.

$$
\mathrm{CGPI}=\frac{\mathrm{C} 1 \mathrm{G} 1+\mathrm{C} 2 \mathrm{G} 2+\cdots+\mathrm{CnGn}}{\mathrm{C} 1+\mathrm{C} 2+\cdots+\mathrm{Cn}}
$$

Table 1. Letter grades and their equivalent grade points applicable for under graduates

\begin{tabular}{ccc}
\hline $\begin{array}{c}\text { Percentage } \\
\text { of marks Obtain }\end{array}$ & $\begin{array}{c}\text { Letter } \\
\text { Grade }\end{array}$ & $\begin{array}{c}\text { Grade } \\
\text { Points }\end{array}$ \\
\hline 80.00 and above & O & 10 \\
$75.00-79.99$ & A & 9 \\
$70.00-74.99$ & B & 8 \\
$60.00-69.99$ & C & 7 \\
$50.00-59.99$ & D & 6 \\
$45.00-49.99$ & E & 5 \\
$40.00-44.99$ & P & 4 \\
Less than 40.00 & F & 0 \\
\hline
\end{tabular}

\section{RESUlt AND DISCUSSION}

The implementation phase of our project is still in progress. Thus far, we have successfully completed the implementation and work of the following factors:

- Final outline of the gadget sheet.

- Automated fetching of marks of the students from database.

- Calculation of Grades and credits for each course.

- Verification and evaluation of marks for special cases (Ordinance for grace marks)

- Generation of grade points for each Course.

- Determination of Grade Performance Index.

- Display of Final Performance of the student in terms of Pass/Fail.

- Veto Power Allocation for Admin Login.

- Creation of individual mark sheets by fetching data from gadget sheet.

- Availability of information of marks to individual student via internet/intranet.

Gadget sheet can be considered as a booklet which consists of marks, student information and grades of all the students belonging to specific organization. Gadget sheet keeps the track of student information in properly listed manner as shown in figure 3. For every student, in gadget sheet marks are generated considering any ordinance applicable to his/her case and grades are generated accordingly for each student.

\section{VIII.CONCLUSION}

We have automated the examination system for generating the gadget sheet and marksheet of the students. In project phase I of semester VII, we have stated that the project facilitates the provision of safe, authenticated and web based system and also automated marksheet generating for grading system and storage and will directly provide the result in form of PDF.

We saw how the existing systems had their own disadvantages as they could be tampered with and once the marksheets were lost, it was difficult to generate new ones.

The rule is given below: 


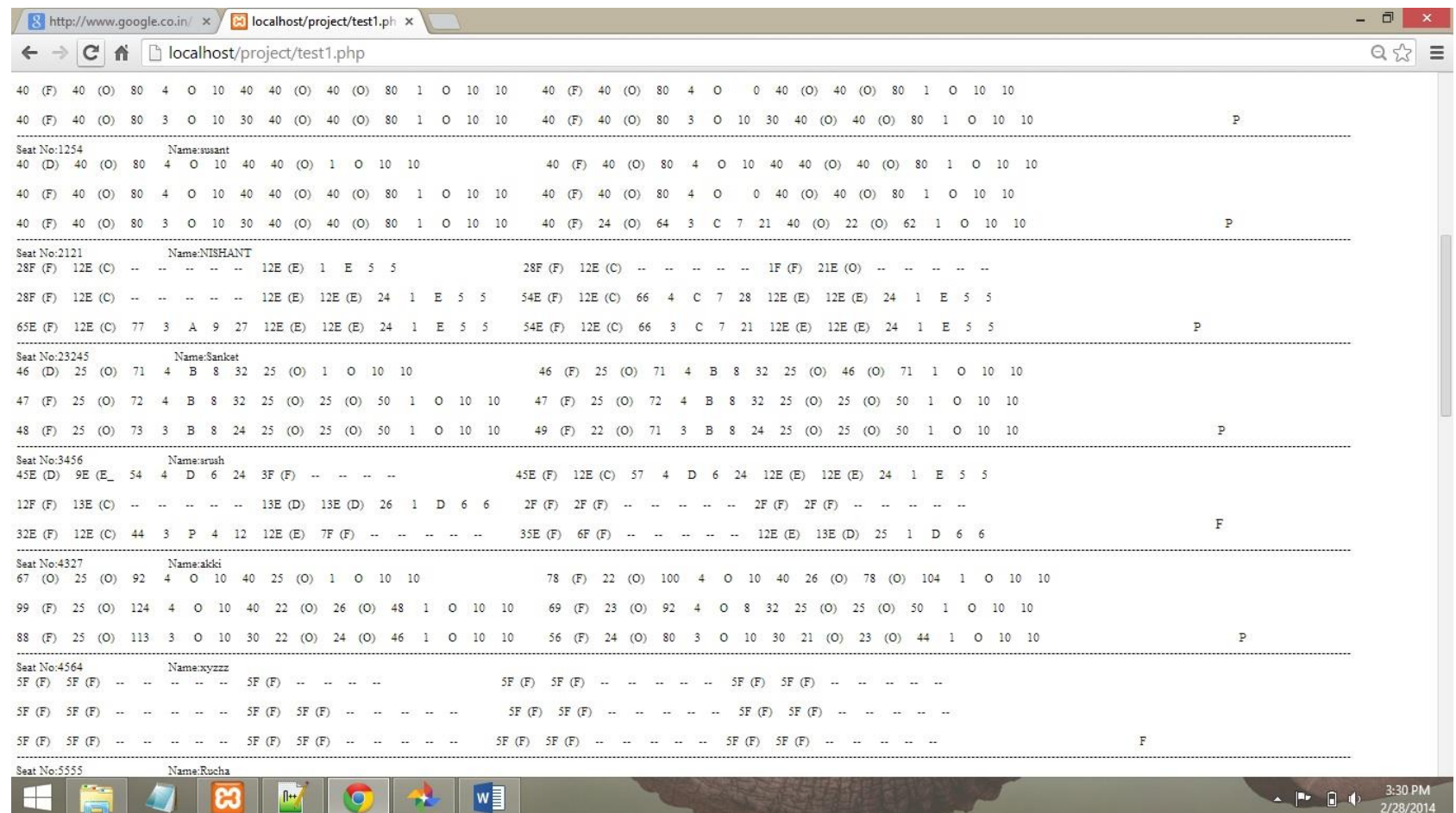

Fig. 3. Screen shot of the implemented gadget sheet.

The Marksheet Generation System aims at developing a mark sheet generation system that will automate the distribution of digitally verifiable student result mark sheets by generating mark sheets in Portable Document Format which very difficult to modify.

This system makes use of the following software is made using very basic programming languages and includes:

- PHP: as server-side scripting language.

- SQL: as database language.

- HTML: at front end.

We have completed the implementation and work of the following factors:

- We have generated the gadget sheet by automated fetching of marks of the students from database.

- Calculation of the grades, credits, grade points of each courses and Grade Performance Index of whole semester considering all the courses.

- Also determined the calculations for verification and evaluation of marks for special cases (ordinances for grace marks in case of failure as per the university rules).

- We have generated Grade Performance Index (GPI) which depicts the final result of the students in particular semester in terms of pointers.

- Display of Final Performance of the student in terms of Pass/Fail.

- Generation of marksheet for individual student for particular semester by fetching data from database and calculating the credits, grades, grade points, grade performance index and final result in terms of pass/fail.
Marksheet is authorized certificate which is consisting of his/her marks for showing progress in respective semester. In our project, mark sheet can be extracted in a PDF which is exclusive feature of our project as shown in Figure 4.

The system automated and generalized the system ensures to reduce manual error by reducing manual efforts. An added asset to the feature of the system is that aims at improving and easing out the work of existing system in very sophisticated way. Also, this system is faster than the earlier methods of manually feeding, calculating and cross-checking the marks.

As this is a web-based system, it can provide services over the Internet on an On-Demand basis, thus making it more accessible. In future the system has sufficient adaptability to couple itself with the already existing mark sheet generation system systems. Also, there will be scope for integrating the report generation technology with this system.

The software is flexible enough to be modified and implemented as per future requirements. The system can be made more secure by providing various security features at different levels. It can also be applied at University level to store results of thousands of students without any glitches and is reliable.

\section{ACKNOWLEDGEMENT}

It has been a sincere desire of every individual to get an opportunity to express his views, skills, attitude and talent in which he is proficient so as to give him satisfaction and confidence in his ability to do or produce something useful for mankind. A Paper is one such avenue through which an engineer gives vent to his 
feelings and expressions. We take this opportunity to express our gratitude towards our internal guide Dr. K.T.V. Reddy, without the motivation and guidance of whom we would have found it difficult to maintain the tempo and enthusiasm. Working with him has been a wonderful learning experience.
We would like to express our deepest gratitude to Exam section staff of PVPPCOE for their encouragement, suggestions and guidance which was instrumental in completing the Paper. We also thank college authorities and professors concerned, who have through meticulous planning, created a comfortable co-existence of the paper and college schedules.

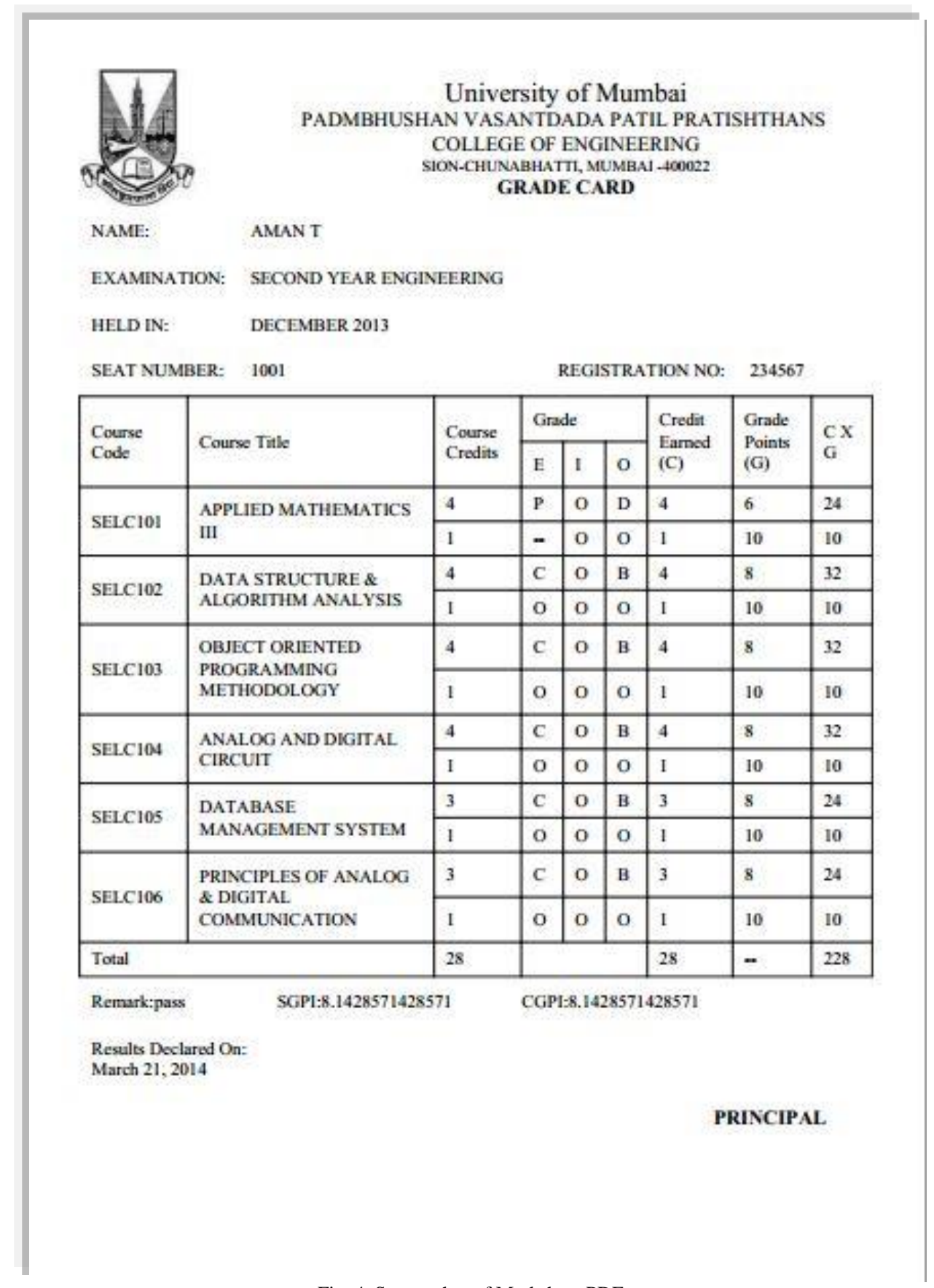

Fig. 4. Screen shot of Marksheet PDF

\section{REFERENCES}

[1] Somdip dey "New Generation of Digital Academic Transcript using encrypted QR Code", Proceedings of IEEE 2013 International Multi Conference on Automation Computing, Communication, Control \& Compressed Sensing (iMaC4s).
[2] "Digital Signature based Mark sheet Generation System" http://srmuniv.ac.in [online] [Retrieved 2013-12-10].

[3] John Enderle, Nicholas Noyes, Abdullah A. AlAqeel "Custom report generator" Proceedings of IEEE 26th Annual Bioengineering Conference,2000.

[4] Mital Doshi "A predictive model for effective higher education", Proceedings of IEEE 2013 International 
Conferanceon Advance in Communication and Computing Technologies (ICACACT), Mumbai.

[5] "Report generator Technical Specification" http://www.isograph-software.com [online] [Retrieved 2014-05-06]

\section{Authors' Profile}

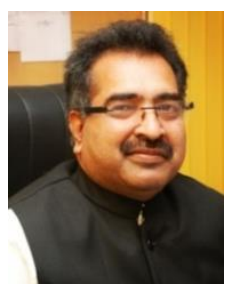

Dr. K. T. V. Reddy received B. Tech degree in Electronics and Communication Engineering from S. V. University and M. Tech. in Communication and Ph.D. in Microwaves / Micro strip Antennas from IIT Bombay. His research interests are Wireless Networks, Mobile networks, RFID, Microwaves, Digital Signal Processing, Satellite Communications, Radar Engineering and Telecommunication Network Design etc. Dr. Reddy is a Fellow Member of IETE, Senior Member of IEEE and life Member of ISTE. He has organized several International and National Conferences. He is the key member to inaugurate over 31 IETE - ISFs in Mumbai University. He severed IETE Mumbai center at various capacities like vice chairman, Treasure, Secretary and Chairman. During 2010 - 2012 he was Council member, IETE HQ, New Delhi. He also served IEEE (AP/ED) Mumbai chapter as Vice Chairman for the year 2004 and 2005. He was selected in Who's who in science and Engineering, USA for the year 2007, 2000 Outstanding Scientists in the world for the year 2008 International Biography Centre, Great Britain and also selected Leading scientists of the World 2008, England. He has developed more than $13 \mathrm{R} \& \mathrm{D}$ projects. He has published over 80 papers in the National / International journals and conferences. He has guided more than 40 projects.

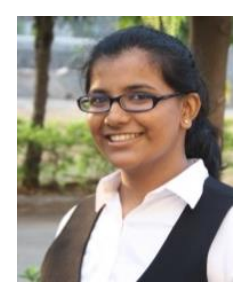

Ms. Srushti Shimpi is pursuing her degree from Mumbai University at Padmabhushan Vasantdada Patil Pratishthan's College of Engineering, Mumbai. Her field of interest is web technology. She has also been member of professional bodies like CSI since 2010 and IEEE since 2012. Being a member of IEEE she worked as Chairperson and Web Administrator of IEEE - PVPPCOE Branch under IEEE Bombay section for an academic year 201213 and organized various workshops and seminars. Also acted as a volunteer at IEEE Bombay Section Student Network (BSSN) under IEEE Bombay section. She has been a core member of Information Technology Student Association (ITSA) for year 2012-13.

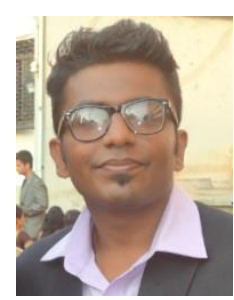

Mr. Tyagraj Sonawane is pursuing his degree from Mumbai University at Padmabhushan Vasantdada Patil Pratishthan's College of Engineering. His field of interest is Information technology. $\mathrm{He}$ has also been member of professional bodies like CSI since 2010.

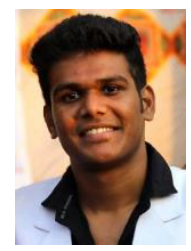

Mr. Sanket Mandare is pursuing his degree from Mumbai University at Padmabhushan Vasantdada Patil Pratishthan's College of Engineering. His field of interest is Information technology. He has also been member of professional bodies like CSI since 2010.

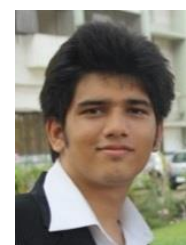

Mr. Aman Trivedi is pursuing his degree from Mumbai University at Padmabhushan Vasantdada Patil Pratishthan's College of Engineering. His field of interest is Information technology. He has also been member of professional bodies like CSI since 2010. 